\title{
Health Care System Reform in Kansas: Context, Challenges, and Capacity
}

\author{
Marcia J. Nielsen ${ }^{*}$ \\ I. INTRODUCTION
}

For decades, the term "health care reform" has marked the political and social landscape of our country. The phrase has varying contextual meanings. For some, it means restructuring how and by whom health care providers are paid. For most, the phrase is grounded in the concept that Americans need access to affordable health care and that many of us-nearly 47 million people in the United States-are uninsured. ${ }^{1}$ This is truly a remarkable statistic because according to the World Health Organization (WHO), the United States spends almost double per capita on health care services than any other country but suffers worse health outcomes on a number of public health indicators. ${ }^{2}$

Recently, both California Governor Arnold Schwarzenegger and Minnesota Governor Tim Pawlenty proposed universal health care coverage for their states' citizens. These proposals came on the heels of last year's well-publicized health care reform plan in Massachusetts, which is now being implemented. ${ }^{3}$ In our own state, Governor Kathleen Sebelius, in her 2007 State of the State Address, called for the Kansas Health Policy Authority (KHPA) to work with her and the Legislature to develop a plan for universal health coverage, increasing Kansans' accessibility to health care. ${ }^{4}$ As the newly-created state agency devoted

\footnotetext{
- Ph.D., M.P.H. The author would like to thank Bob Hiller, J.D., Marta Linenberger, J.D., and Megan Ingmire for their assistance in preparing this article.

1. Press Release, U.S. Census Bureau, Income Climbs, Poverty Stabilizes, Uninsured Rate Increases (Aug. 29, 2006), available at http://www.census.gov/Press-Release/www/releases/ archives/income_wealth/007419.html.

2. World Health ORganization, The World Health Report 2000, Health Systems: IMPROVING PERFORMANCE 152-55 (2000)

3. Elizabeth Davidz, Healthcare: Diagnosing the Problem but Not the Remedy, MARKETWATCH, Jan. 25, 2007, available at http://www.marketwatch.com/news/story/healthcareproblems-agreed-solution $2 \% 7 \mathrm{D}$.

4. Governor Kathleen Sebelius, 2007 State of the State Address, Kansas Tomorrow: Fulfilling Our Promise (Jan. 10, 2007), available at http://www.governor.ks.gov/news/sp-stateofstate2007. htm.
} 
to coordinating health and health care for Kansans, it is the KHPA's responsibility to help lead this charge over the coming days, weeks, months, and even years. Kansas, like many states, however, faces several challenges within the context of a failing national health system. By more broadly understanding the context of state reforms in a national system, we can develop health reform plans and set realistic expectations for policies and priorities that reflect the values of Kansans.

\section{A FAILING NATIONAL HeAlth SYSTEM}

The U.S. health care system is not a true "system." Health care delivery is fragmented among its many stakeholders, resulting in lack of coordination between providers, purchasers, and consumers. Four concrete and interrelated areas-insurance affordability, access to care, health care efficiency and quality, and health promotion and wellnessmust be realigned in order to improve health outcomes and control costs. Since the failed Clinton reform efforts of the early 1990s, federal leadership has been minimal on many of these issues. States have thus taken a leadership role as "laboratories of democracy" pushing for health reform. However, states are unable to tackle many of the larger issues that necessitate leadership at the national level. The fact that almost half of all health insurance is regulated by the federal government through the Employee Retirement Income Security Act (ERISA) ${ }^{5}$ limits what states can do. More federal leadership is needed to develop interoperable health information technology, to facilitate cost containment strategies across public and private health insurance programs, and to assist with the growing costs of Medicare and Medicaid attributable to an aging population. Only the federal government can resolve interstate issues that further fragment the delivery of health care services across state lines.

\section{A. A Universal Health System?}

Many argue that a national health care system in the United States already exists. Through a federal law called the Emergency Medical Treatment and Active Labor Act (EMTALA), ${ }^{6}$ all Americans have universal access to health care services via hospital emergency

5. Employee Retirement Income Security Act, 29 U.S.C. $\S \S 1001-1461$ (2000).

6. 42 U.S.C. $\$ 1395 \mathrm{dd}(2000)$. 
departments. $^{7}$ Anyone coming through the emergency room doors of a U.S. hospital must be evaluated and stabilized. ${ }^{8}$ Of course, this system for universal access is the least efficient and most expensive use of medical and financial resources. Many of those treated in emergency rooms are sicker than average patients, and primary care would be a more appropriate setting for medical management. ${ }^{9}$ Thus, from a financial perspective, this argument makes little sense.

Patients who are uninsured are most likely to use hospital emergency rooms to secure access to health care services. Statistics show that the number of uninsured persons has steadily increased since 2000 , growing to 47 million uninsured persons in 2005 alone. ${ }^{10}$ If this trend continues, the number of uninsured persons is expected to increase to 56 million in 2013." The growing number of uninsured persons is related to the increasing costs of health insurance, the decreasing number of employers providing health insurance, and the overall costs of health care services. ${ }^{12}$ Compared with other economic indicators, such as workers' earnings and overall inflation, health insurance premiums have sharply increased in recent years. ${ }^{13}$ This creates a heavy financial burden for consumers that many cannot afford. Indeed, "[ $\mathrm{t}]$ here is a cost to society. When an uninsured person goes to a public hospital or clinic, an emergency room, or a private physician for care and cannot pay the full cost, some of the bill is passed on to those who do pay-through higher insurance premiums and in the form of taxes spent on our public insurance programs, Medicare and Medicaid. One way or another, we all pay indirectly for having a large and growing uninsured population."14

7. See 42 C.F.R. $\S 489.24$ (a) (2006) (“[T] he hospital must [p]rovide an appropriate medical screening examination" and "provide any necessary stabilizing treatment.").

8. Hospitals that receive Medicare funding must treat all patients who come to the emergency room. 42 U.S.C. $\$ 1395$ dd.

9. The Commonwealth Fund Comm'n on a High Performance Health System, Why Not IN THE BEST? RESULTS FROM A NATIONAL SCORECARD ON U.S. HEALTH SySTEM PERFORMANCE 24 (Sept. 2006).

10. The Commonwealth Fund, 47 Million Uninsured in 2005; Increasing Steadily Since 2000, http://www.cmsf.org/chartcartcharts/chartcartcharts_show.htm?doc_id $=405502$ (last visited Apr. 1, 2007).

11. Id

12. KAISER COMM'N ON MEDICAID AND the UNINSURED, HENRY J. KaISER FAMILY Found., Uninsured in America: Key Facts About Gaps in Health Insurance Coverage, http://www.kff.org/ uninsured/1340-uninsured.cfm (last visited Mar. 16, 2007) [hereinafter KAISER COMM'N ON MEDICAID].

13. Gary Claxton et al., Henry J. Kaiser family foundtion and Health Research AND EdUCATIONAL TRUST, Employers Health Benefits Annual Survey 18 (2006), http://www. kff.org/insurance/7527/upload/7527.pdf.

14. KAISER COMM'N ON MEDICAID, supra note 12. 


\section{B. Improving Quality and Controlling Costs}

Health care efficiency and quality are intertwined. Limited use of information technology in Kansas and across the United States limits our ability to coordinate care, promote patient safety, and utilize best practices and evidence-based medicine. Redundancy in care and lack of quality care creates unnecessary financial burdens on the patient and providers and can lead patients to forego treatment altogether. Health care administration in the form of excess paperwork also contributes to inefficiency.

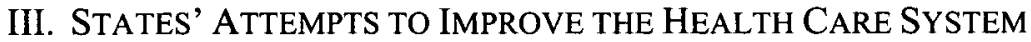

The lack of federal action to improve health care affordability, access, and quality has led many states to take innovative steps toward reform. States are exploring premium assistance programs, developing new insurance products, and experimenting with tax credits, specialized coverage for children, and increased access to community health centers. Premium assistance programs generally consist of subsidies to lowincome individuals to purchase health insurance products in the private market. ${ }^{15}$ New products include high-deductible, consumer-driven health plans. Such plans may be more affordable for small businesses and selfemployed individuals. Tax credits are available in some states for small businesses that contribute to employee health insurance plans. Other states have increased access to care for children through Medicaid and State Children's Health Insurance Program (SCHIP) expansions and innovative Section 1115 waivers. ${ }^{16}$ Community Health Centers are also seen as an important safety net for the uninsured and serve as a viable care option in lieu of emergency department treatment. ${ }^{17}$

\section{CAPACITY: WHAT IS HAPPENING IN KANSAS?}

Many of the issues facing the health care system on a national level are similar to ones we are facing in Kansas. Our health care and insurance costs continue to grow, making it difficult for small businesses

15. See Christopher Keating, Plans Meet Partisan Diagnoses, HarTford Courant, Jan. 27, 2007, at Bl (discussing the cost of a proposed "premium assistance" program in Connecticut).

16. Vincent C. Caponi, Speaking Up for Uninsured Kids, INDIANAPOLIS STAR, Jan. 19, 2007, at 13.

17. Center for Best Practices, National Governors association ImProving and INCREASING ACCESS to CARE: STATE HEALTH COVERAGE EXPANSIONS SINCE 2004 7-8 (2006). 
and individuals to afford insurance. Employer-sponsored health insurance is declining. We have limited use of information technology and a limited focus on health promotion and wellness.

In $2005,67 \%$ of Kansans received their health care coverage from employers. ${ }^{18}$ That number was higher between 2000 and 2004. During that time, many Kansans lost employer-sponsored health coverage while the number of those covered by Medicaid or SCHIP rose. ${ }^{19}$ Currently, over $10 \%$ of Kansans receive coverage through Medicaid, while approximately $11 \%$ remain uninsured. $^{20}$

Health care costs in Kansas and throughout the United States continue to increase. Between 2003 and 2005, the cost for pharmaceuticals in Kansas rose by $\$ 100$ million. ${ }^{21}$ The cost of inpatient care jumped from approximately $\$ 175$ million in 2004 to nearly $\$ 250$ million in $2005 .^{22}$

We have limited use of information technology due to the lack of interoperability, the expense associated with the purchase of technology, and the concern about privacy protections. As of April 2005, slightly more than $20 \%$ of physicians across Kansas used electronic clinical information. Kansas hospitals reported that $51 \%$ had access to electronic lab results, $34 \%$ had electronic imaging systems in place, and $24 \%$ reported electronic medication administration records. ${ }^{23}$

There is a significant and increasing need for health and wellness promotion and disease prevention wellness in our state, with a focus on individual health behavior change and community supports for health. This is critical not only to improve Kansans' overall health status, but also to control long term health care costs. In Kansas and across the nation, the steady increase in the number of obese or overweight individuals threatens our health and the health of our children. ${ }^{24}$ In addition, the use of tobacco continues to negatively impact people's

18. KAISER COMM'N ON MEDICAID AND UNINSURED, THE HENRY J. KAISER FAMILY Found., STATE MEDICAID [FACT SHEETS]: KANSAS \& UNIFIED STATES, http://www.kff.org/mfs/medicaid. jsp?rl=ks\&r2=US [hereinafter KAISER COMM'N].

19. Id.

20. KAISER COMM'N, supra note 18 .

21. Id.

22. Id.

23. eHEalth INitiative Found., Kansas Health INFormation EXChange Roadmap: BRIEFING PAPER, ii (2005), http://www.governor.ks.gov/LtGov/healthcare/items/KansasHITBrief. pdf (preview copy prior to final formatting Jan. 10, 2006).

24. Healthy Kansans 2010, Learning fRom the PAST, PReParing For the FutURE: ENCOURAGING CHANGE FOR HEALTHIER KANSANS 11 (2006), http://www.healthyKansans2010. org/KPHAFiles/Final\%20Report\%2011-7-06.pdf. 
health. In Kansas, nearly $20 \%$ of adults smoke cigarettes. ${ }^{25}$ We need to embrace strategies that support those who are trying to quit smoking while protecting those who do not smoke from the effects of secondhand smoke. Tobacco control must continue to be a major public health priority and health care cost-control strategy.

\section{KANSAS LEADERSHIP}

In terms of state leadership, Kansas strives to be among the forefront. In 2005, the Legislature created the KHPA. Its mission, as outlined by statute, is to develop and maintain a coordinated health policy agenda, combining the effective purchasing and administration of health care with health-promotion-oriented public health strategies-using data to drive health policy. ${ }^{26}$

The KHPA was established on July 1, 2005, as a new agency within the Executive Branch. ${ }^{27}$ The KHPA is responsible for coordinating a statewide health policy agenda that incorporates effective purchasing, administration, and health promotion strategies. All health insurance purchased by the State is now combined under the KHPA, including publicly funded programs (Medicaid, SCHIP, and Medikan) and the State Employee Health Benefits Plan (SEHBP). The KHPA is responsible for compiling and distributing uniform health care data in order to provide health care consumers, payers, providers, and policymakers with information regarding trends in the use and cost of health care to improve decision making.

\section{A. Independent Agency}

The KHPA is an independent state agency operating under an integrated and diverse governing board that serves as the agency head. The board is designed to provide governance and innovative health policy direction outside the spotlight of partisan politics to advance a collective agenda for health. ${ }^{28}$ The KHPA board consists of nine voting board members (three members appointed by the Governor and six members appointed by legislative leaders). There are also seven nonvoting (ex officio) members, including the Secretaries of Health and Environment, Social and Rehabilitation Services, Administration, and

25. See id. at 22 (stating that " $17 \%$ of Kansas adults are current smokers")

26. S.B. 272, $81 \mathrm{st} \mathrm{Leg.,} \mathrm{Reg.} \mathrm{Sess.} \mathrm{(Kan.} \mathrm{2005).}$

27. Id.

28. Id. 
Aging; the Director of Health in the Kansas Department of Health and Environment; the Commissioner of Insurance; and the Executive Director of the KHPA. Collectively, board members have experience in administering, purchasing, and providing health care services and promoting public health.

In 2006, the KHPA became the sole state Medicaid Agency for Kansas. The KHPA also assumed responsibility for the Ticket to Work/Working Healthy Program, the Medicaid Management Information System, the Medicaid Drug Utilization Review and its related programs, the Kansas SEHBP, the Kansas Employee Workers' Compensation Program, the Health Care Data Governing Board, and the Kansas Business Health Partnership. ${ }^{29}$

\section{B. Three Major Health Programs}

The three major health programs under the KHPA include: (1) Medicaid (Title XIX); (2) SCHIP (Title XXI); and (3) The SEHBP and the State Workers' Compensation Program.

\section{Medicaid (Title XIX)}

Medicaid is a federal/state matching funds program used to purchase preventive, primary, and acute health services for low-income individuals, children, and families. It also pays for certain long-term care services, like nursing homes, for the elderly or people with disabilities. The federal government provides approximately $60 \%$ of the cost of Medicaid services. In other words, for every Medicaid dollar spent in Kansas, about sixty cents come from the federal government; the state provides the remaining forty cents. Medicaid is an open-ended entitlement for states. That is, as long as covered services are provided to eligible beneficiaries as specified in the State Medicaid Plan, the federal government must participate in sharing the costs of those services.

\section{SCHIP (Title XXI)}

SCHIP provides health care coverage for low-income children who do not qualify for Medicaid. The federal government provides approximately $72 \%$ of the cost of SCHIP and the state contributes the 
remaining $28 \%$, as well as any excess spent above the federal allotment. Unlike Medicaid, SCHIP is not open-ended; states are awarded yearly allotments.

Medicaid services are purchased through either a fee-for-service model or a managed care model. In the fee-for-service model, the state pays the provider directly. In the managed care model, the state pays a managed care organization (MCO) a monthly payment for each beneficiary. The MCO contracts with providers and pays them for services. SCHIP is provided only in a managed care model. Medicaid managed care and SCHIP are combined into a program called HealthWave, designed to provide one seamless managed care option for families.

\section{The SEHBP and the State Workers' Compensation Program}

SEHBP and the Workers' Compensation Program broaden the KHPA and set the stage for uniform and comprehensive reform. Groups provided health care benefit plans through state plans include active state employees, individuals with COBRA coverage, retirees and groups qualifying for coverage under state regulations, such as teachers, employees of cities, townships, and counties. The KHPA manages the State Workers' Compensation Self Insurance Fund, which provides medical care, disability and death benefits, return to work options, and customer service to state employees covered under the Kansas Workers' Compensation Act.

\section{KHPA'S STRATEGIC GOALS}

The KHPA Board devoted a significant amount of time during its first year of operation in 2006 to understanding those programs under its purview, and to developing priorities for the agency and the state. In the fall of 2006, the Board approved six vision principles and a set of health indicators as required by statute. ${ }^{30}$ The vision principles and health indicators, discussed at length by Board members in public meetings, are intended to provide a framework for evaluating and improving health policy in Kansas.

These principles range from providing access to care, to stewardship, to education, and they will provide direction to the KHPA in its ongoing 
work and in the development of new initiatives and programmatic proposals.

\section{A. KHPA's Vision Principles}

KHPA's six vision principles are: (1) access to care; (2) quality and efficiency in health care; (3) affordable and sustainable health care; (4) promoting health and wellness; (5) stewardship; and (6) education and engagement of the public. ${ }^{31}$

\section{Access to Care}

Every Kansan should have access to patient-centered health care and public health services ensuring the right care, at the right place, and the right price. Health promotion and disease prevention should be integrated directly into these services.

\section{Quality and Efficiency in Health Care}

The delivery of care in Kansas should emphasize positive outcomes, safety, and efficiency, and should be based on best practices and evidence-based medicine.

\section{Affordable and Sustainable Health Care}

The financing of health care and health promotion in Kansas should be equitable, seamless, and sustainable for consumers, providers, purchasers, and government.

4. Promoting Health and Wellness

Kansans should pursue healthy lifestyles with a focus on wellnessincluding physical activity, proper nutrition, and refraining from tobacco use- as well as a focus on the informed use of health services over their life course.

31. A diagram of KHPA's six vision principles is included infra. 
5. Stewardship

The KHPA will administer the resources entrusted to us by the citizens and the State of Kansas with the highest level of integrity, responsibility, and transparency.

6. Education and Engagement of the Public

Kansans should be educated about health and health care delivery to encourage public engagement in developing an improved health system for all.

\section{B. Health Indicators}

As required by statute, the KHPA Board, in collaboration with our partner agencies in Kansas, developed a set of health indicators to track the improvement of health in Kansas over time. Our partner agencies include the Department of Social and Rehabilitation Services, the Department of Health and Environment, the Department of Aging, and the Department of Insurance. Each set of health indicators correlate with one of the six vision principles. These indicators will include baseline and trend data on health care, health outcomes, healthy behaviors, KHPA operational integrity, and health costs. Determining specific measures for these indicators will allow the KHPA to track changes over time and assess the impact of state health policy initiatives on health improvement and cost containment. Information gathered from these indicators will form the framework for future action and ensure that health policy in Kansas moves in the right direction.

\section{VII.CONCLUSION}

The KHPA's success in implementing health change and transforming our health system will depend not only on data and guidance by the vision principles, but also on leadership, collaboration, and transparency. Agency capacity is essential to advancing more innovative reforms. Agency transparency that is focused on partnerships with stakeholders, the Governor's office, and the Legislature will be the key to creating an environment in which reforms can be embraced and adopted as law.

As outlined previously, the challenges that exist within the current U.S. health system are significant and require states to adopt integrated and innovative approaches to improving health. Short-term reforms and 
long-term transformation are both necessary to accomplish this goal. KHPA's goals are to explore policy options that maintain and strengthen current programs, fit within the larger board vision principles, and improve comprehensive reform. Our vision to coordinate health and health care for a thriving Kansas requires that we advance policy options supported by data that are developed with stakeholder input and focused on affordable patient-centered policies, and that integrate health promotion with the health care delivery.

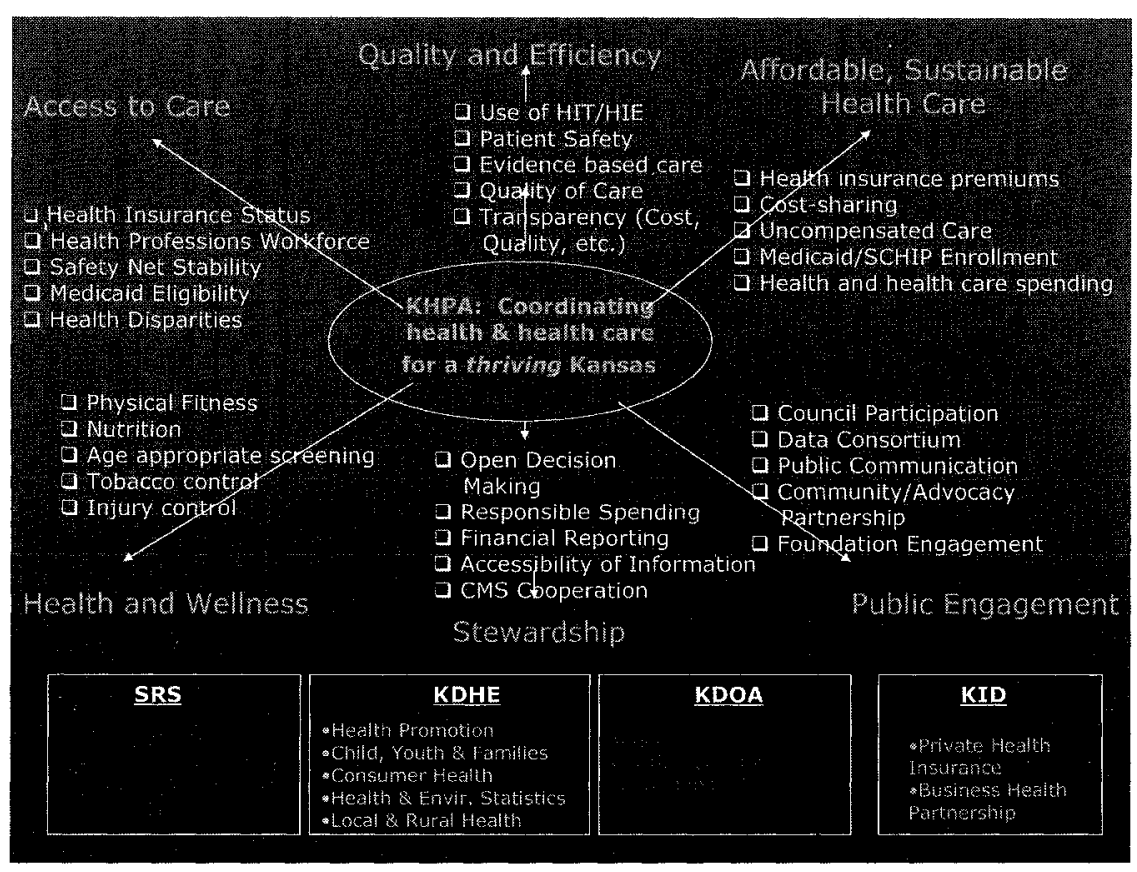


